\title{
Uzgoj, nutritivna svojstva i korištenje žižule (Ziziphus jujuba Mill.)
}

\section{Sažetak}

Žižula (Ziziphus jujuba Mill.) je voćna vrsta porijeklom iz Kine gdje se uzgaja gotovo 4000 godina. Po broju stabala najbrojnija je voćna vrsta u Kini. Plod je koštunica koji može biti oblog ili izduženog oblika, od veličine višnje pa do veličine šljive i karakterističnog je slatko-kiselog okusa. Žižula je izuzetno specifična zbog svoje neobične strukture izbojaka te kasnijeg kretanja i ranijeg završetka vegetacije u odnosu na ostale voćne vrste. Plodovi su izuzetno bogati vitaminom C. Neizostavan je dio prehrane u Kini te ima veliku važnost u tradicionalnoj medicini za liječenje mnogobrojnih bolesti. U Hrvatskoj se žižula može pronaći u Istri i Dalmaciji gdje se najčešće koristi kao samostalno stablo u dekorativne svrhe. Najpovoljnije vrijeme sadnje za žižulu je u proljeće u vrijeme bubrenja pupova. Berba žižule počinje od kraja kolovoza i traje do studenoga ovisno o sorti. Plodonošenje počinje u drugoj godini nakon sadnje, a punu rodnost nakon 4 do 5 godina. U voćnjacima se prirodi kreću od 18 do $50 \mathrm{~kg}$ po stablu. Zbog svoje izuzetne otpornosti na sušu te prilagođenosti mediteranskoj klimi, žižula je izuzetno zanimljiva voćna vrsta za uzgoj.

Ključne riječi: korištenje, nutritivna vrijednost, uzgoj, žižula

\section{Uvod}

Žižula (lat. Ziziphus jujuba Mill.) je voćna vrsta porijeklom iz Kine (Liu, 2006), poznata je i kao kineska datulja zbog sličnosti suhog ploda sa suhim plodom palme datulje (Phoenix dactylifera). U Kini je naziv za datulju,,zongzao" što u prijevodu znači palmina žižula.

Pripada redu ruža (lat. Rosales) i porodici pasjakovki (lat. Rhamnaceae) te je najvažnija kultivirana vrsta u rodu Ziziphus (Liu i sur., 2014). Jedna je od najstarijih kultiviranih vrsta voća u Kini i svijetu. Smatra se da potječe iz srednjih i nižih područja oko Žute rijeke te se uzgaja u Kini više od 4000 godina. Konzumira se duže od 7000 godina što se može zaključiti iz fosiliziranih ostataka plodova pronađenih na neolitičkom nalazištu blizu Egoubeigang-a, u provinciji Henan (Qu i Wang, 1993; Guo i Shan, 2010; Liu, 2006). Selekcioniranjem stabala kisele ili divlje žižule (Ziziphus spinosa) kroz povijest, nastala je Ziziphus jujuba Mill. što se može ustanoviti iz fosila, arheoloških iskapanja, povijesnih knjiga i suvremenih istraživanja (Qu i Wang, 1993; Liu i Wang, 2009).

Žižula se postupno širila unutar Kine i okolnih zemalja, a 'Putem svile' je donesena u Europu oko 1. stoljeća (Liu, 2006; Lyrene, 1979). U Sjedinjene Američke Države je unesena iz Europe 30ih godina 19. stoljeća. U Kini se pokazala kao dobra medonosna biljka, dok u drugim dijelovima svijeta ne privlači pčele.

U Hrvatskoj je poznata kao obična žižulja, žižulja, čičimak, činguljin, čičindra, ili kineska datulja. Raste od Istre do najjužnijih dijelova Hrvatske te je u prošlosti bila zastupljenija nego danas, prvenstveno kao ukrasna biljka.

Dorian Sušanj, mag. ing.agr., doc. dr. sc.Vesna Očić, doc. dr. sc. Jelena Gadže, prof. dr. sc. Snježana Bolarić, doc. dr. sc. Kristina Batelja Lodeta,

Sveučilište u Zagrebu Agronomski fakultet, Svetošimunska cesta 25, 10000 Zagreb, Hrvatska

doc.dr.sc.JosipGugić, SveučilišteuSplitu,Sveučilišniodjelzastudijemora, RuđeraBoškovića37,21000Split,Hrvatska

Autor za korespondenciju: kbatelja@agr.hr 


\section{Proizvodnja žižule}

Kina je najveći svjetski proizvođač žižule s gotovo 99\% ukupne svjetske proizvodnje i jedina zemlja koja izvozi žižulu (Wang i sur., 2016). Godišnja proizvodnja se povećala 15 puta od 1980. godine do 2015. godine. Ukupno 90\% proizvodnje je koncentrirano u 6 sjevernih provincija od kojih je najvažnija Xinjiang, gdje se žižula uzgaja na 483,628 hektara te ima godišnju proizvodnju preko 2,5 milijuna tona svježih plodova (Chen i sur., 2017). Ukupne površine nasada žižule u Kini prostiru se na preko 2 milijuna hektara, a godišnja proizvodnja iznosi preko 6 milijuna tona.

U značajnim količinama uzgaja se još jedino u Južnoj Koreji, na površini od oko 5000 hektara s godišnjom proizvodnjom oko 20,000 tona (Liu, 2006).

Žižula se u ostalim zemljama većinom uzgaja u svrhu istraživanja ili kao ukrasna biljka. $\mathrm{Na}$ području Mediterana se najčešće uzgaja kao ukrasna biljka dok se u Australiji, Iranu, SAD-u, Turskoj i Meksiku podižu nasadi u svrhu komercijalne proizvodnje žižule.

Žižula je u Hrvatskoj zapostavljena voćna vrsta koja se uzgaja primarno u dekorativne svrhe. Nalazimo je od juga Dalmacije pa do sjevera Istre. $U$ te krajeve su je donijeli pomorci iz istočnih krajeva. U okolici Skradina se nalaze stabla stara više stotina godina. U prošlosti je svaki ljetnikovac imao u vrtu žižulu zbog dekoracije, ali i zbog nutritivnih svojstava (Prgomet, 2014). $U$ jesen se ponegdje na tržnicama znaju pronaći plodovi po cijeni do čak 40 kn po kilogramu.

U novije vrijeme se podižu ekološki nasadi gdje se žižula uzgaja u konsocijaciji s maslinom, zbog razvoja predatorske osice Psyttalia concolor koja parazitira ličinke maslinine muhe (Bactrocera oleae).

\section{Ekološki uvjeti za uzgoj žižule}

Žižula je izuzetno prilagodljiva voćna vrsta koja ima široku ekološku valenciju, no ipak otpornost ovisi o sorti, starosti biljke i načinu uzgoja.

Uspijeva na plitkim i dubokim tlima, tlima siromašnim i bogatim organskom tvari. Tolerira $\mathrm{pH}$ tla od 5,0 do 8,5. Raste na tlima koja su izuzetno siromašna organskom tvari, na kojima je uzgoj drugih voćnih vrsta nemoguć (Yao, 2012; Liu, 2006).

Za uzgoj kvalitetnih plodova i visok prirod neophodno je dobro drenirano pjeskovito tlo dubine preko $50 \mathrm{~cm}$, visok sadržaj organske tvari, $\mathrm{pH}$ tla 5,5 do 8, a sadržaj $\mathrm{NaCl}$ u tlu treba biti manji od 0,1\% i ukupni sadržaj soli u tlu manji od 0,3\% (Liu, 2002; 2004).

Intenzivna proizvodnja je na područjima sa srednjom godišnjom temperaturom od $8{ }^{\circ} \mathrm{C}$ do 22 ${ }^{\circ} \mathrm{C}$. Žižula može tolerirati zimi temperature od $-30{ }^{\circ} \mathrm{C}$ do $-38{ }^{\circ} \mathrm{C}$, a ljeti temperaturne maksimume do $48,9{ }^{\circ} \mathrm{C}$. Za zametanje plodova je potrebna srednja dnevna temperatura iznad $20^{\circ} \mathrm{C}$. Razvoj ploda zahtjeva srednje dnevne temperature iznad $24{ }^{\circ} \mathrm{C}$ do $25^{\circ} \mathrm{C}$. Kada srednja dnevna temperatura padne ispod $15^{\circ} \mathrm{C}$, započinje opadanje listova i biljka ulazi u fazu mirovanja (Zhao i Liu, 2016).

Može preživjeti u uvjetima velike vlage, ali isto tako i velike suše (Ming i Sun, 1986; Liu, 2004). Mnoge sorte se uzgajaju u sjeverozapadnoj Kini gdje se godišnja količina oborina kreće ispod $200 \mathrm{~mm}$ godišnje pa sve do $650 \mathrm{~mm}$. Podnosi i velike količine oborina i visoku vlagu u zraku (Qu i Wang, 1993; Liu, 2006).

Za zametanje i rast plodova je potrebna veća relativna vlažnost zraka i veća količina vode u tlu, stoga se u takvim uvjetima očekuju najviši prirodi. Problem nastaje ako su velike količine oborina u fazi dozrijevanja plodova, jer onda dolazi do pucanja i bolesti plodova (Liu, 2006).

Brzina vjetra do $6 \mathrm{~m} / \mathrm{s}$ u vrijeme vegetacije nije štetna ni za jedan dio biljke. Najotporniji su rodni izbojci i lišće, dok su cvjetovi i zreli plodovi osjetljiviji na vjetar. Otpornost na vjetar ovisi o: sorti, starosti biljke, gustoći sadnje, količini plodova i položaju voćnjaka.

Najveći prirodi su na područjima do 400 m nadmorske visine na sunčanim položajima južne ekspozicije (Liu i sur, 1992a). Može rasti sve do 2000 m nadmorske visine, ali nakon 500 m nadmorske visine prirod i kvaliteta plodova opadaju te dolazi do usporenog rasta koštice ploda. 


\section{Uzgoj žižule}

Tri su načina sadnje u svrhu komercijalnog uzgoja žižule. Tradicionalni voćnjaci se formiraju s razmacima sadnje $4 m-5 m \times 5 m-6 m$, intenzivni voćnjaci s razmacima sadnje $2 m-3 m$ $\times 3 m-4 m$ i voćnjaci s različitim voćnim vrstama. U novije vrijeme u Kini se podižu nasadi s razmacima sadnje od $1 m-2 m \times 4 m$ do čak 0,5 m-0,7 m x $1 m$ u super intenzivnim zaštićenim nasadima. Razlog tome je što se veličina stabla žižule prilično lagano kontrolira. Žižula se uzgaja u obliku popravljene vaze ili popravljene piramidalne krošnje s visinom debla od 70 do $80 \mathrm{~cm}$, a dosta je proširen i uzgoj u obliku grma (Miljković, 1991).

Najpovoljnije vrijeme sadnje za žižulu je u proljeće za vrijeme bubrenja pupova. U tropskim i subtropskim područjima sadnja se može obaviti i u jesen. Na vjetrovitijim i sušim područjima potrebno je nakon sadnje izvršiti prikraćivanje na oko $30 \mathrm{~cm}$ kako bi se smanjila evaporacija vode i povećala mogućnost primanja (Liu, 2002).

$U$ prirodi se razmnožava pomoću korijenovih izdanaka ili sjemenom. U nasadima se razmnožava vegetativno, pomoću zelenih ili zrelih reznica te za razliku od većine voćnih vrsta na taj način dolazi u rod već u drugoj godini. Najrašireniji način razmnožavanja je pomoću korijenovih izdanaka ili cijepljenjem na kiselu žižulu kao podlogu (Mousavi i sur., 2017; Yao, 2013).

Cijepljenje žižule je opisano u najstarijoj kineskoj knjizi o poljoprivredi 'Qi Min Yao Shu' (Osnovne poljoprivredne vještine za običnog čovjeka), koja je izdana prije 1400 godina (Guo i Shan, 2010). Najčešći način cijepljenja je u zrelo: na jezičac, pod koru i u procijep (Yao, 2013). Okuliranje se ne koristi zbog specifične strukture izbojaka i pupova, ali i zbog tanke kore stabla.

Korištenje kombinacije organskih i mineralnih gnojiva sa povećanom dozom kalija, a s manje dodatnog pojedinačnog dušika i fosfora može biti najbolja kombinacija za postizanje veće koncentracije fenola, i antioksidatnsa u plodovima žižule i postizanje visokog priroda (Wu i sur. 2013).

Žižula je općenito gledano, laka za rezidbu i održavanje, ali se treba držati nekih osnovnih načela. Za razliku od jabuke ili breskve, ukoliko se jednogodišnji izbojak prikrati do sredine, ispod tog mjesta neće doći do rasta novih izbojaka. Kako bi se potaknuo rast potrebno je ukloniti izbojak ispod mjesta reza. Žižula je heliofit stoga je potrebno rezidbu činiti svake godine kako bi se osigurala ravnomjerna osunčanost krošnje, a time količina i kvaliteta plodova (Yao, 2012). Zbog kasne cvatnje, rijetko stradava od mraza pa rijetko dolazi do izostanka plodonošenja. Vegetacija kreće u prosjeku 4 do 6 tjedana kasnije od klasičnih voćnih vrsta, a cvate kasnije i puno duže u odnosu na njih.

Plod je koštunica s jednom košticom unutar koje se nalaze do dvije sjemenke. Veličina ploda žižule se razlikuje ovisno o sorti, a veličina se kreće od 1 do $4 \mathrm{~cm}$ u promjeru. Plod može biti okrugao, eliptičan, jajolik, duguljast, jabukolik ili nekog nedeterminiranog oblika (Liu, 2006). Žižula iznimno brzo dolazi u rod, već u drugoj godini nakon sadnje, a u nekim slučajevima čak i u godini sadnje ili cijepljenja.

Berba žižule počinje od kraja kolovoza i traje do studenoga ovisno o sorti. Plod zriobom mijenja boju iz tamno-zelene u žuto-zelenu. Daljnjom zriobom nastaju smeđe i crvene točkice na plodu i peteljci sve dok plod u potpunosti ne postane smeđe boje. Nekoliko dana nakon što postigne smeđu boju, plod počinje mekšati i površina postaje naborana.

Plodovi se mogu konzumirati u raznim fazama zrenja, od žuto-zelenih do potpuno smeđih. Svježe ubrani plodovi se mogu čuvati dva tjedna ili duže na temperaturi od $5^{\circ} \mathrm{C}$ bez gubitka kvalitete. Plodovi namijenjeni sušenju se beru kada su potpuno zreli i smeđe boje. Na područjima gdje je velika vlaga, berba se obavlja kada su plodovi potpuno zreli i suše se što je moguće prije kako bi se izbjegla pojava gljivica ili plijesni (Yao, 2012).

Berba plodova za konzumaciju u svježem stanju se obavlja ručno kako bi oštećenja na plodovima bila minimalna, dok se za plodove koji su namijenjeni sušenju koriste pomagala slična 
kao u berbi masline. Pucanje plodova je fiziološki poremećaj do kojeg dolazi zbog prekomjerne opskrbe vodom u fazi sazrijevanja plodova te može doći do gubitka cjelokupnog priroda u godinama s izuzetno puno kiše. Guo i Shan (2010) napominju kako svakih pet godina dolazi do ozbiljnog pucanja plodova i truleži plodova u okrugu Laoling pri čemu se gubi do $40 \%$ priroda za tu godinu. Preventivne mjere su: pravilno navodnjavanje u vrijeme vegetacije, posebice $u$ vrijeme sazrijevanja plodova i odabir sorti koje su otporne na pucanje plodova. Žižula je izuzetno rodna voćka. Cvjeta u godini sadnje, ili cijepljenja, a neke sorte i plodonose u istoj godini. Većina sorti počinje plodonošenje $u$ drugoj godini nakon sadnje, a puna rodnost dolazi nakon 4 do 5 godina.

U voćnjacima se prirodi kreću od 18 do $50 \mathrm{~kg}$ po stablu, a u nekim slučajevima i više, ovisno o veličini stabla i sustavu uzgoja. Proizvodni vijek u voćnjaku je 50 i više godina. Neki primjerci u Kini stari su preko 1000 godina i još plodonose (Yao, 2012).

Najraširenija bolest žižule u Kini je 'vještičja metla' koja je osim u Kini, raširena u Japanu i Južnoj Koreji (Guo i Shan, 2010; Jung i sur.., 2003; Zhou i sur., 1998). Može uništiti cijeli voćnjak, a spriječiti se jedino može dobrim preventivnim mjerama. 'Vještičju metlu' uzrokuje fitoplazma Canditus Phytoplasma ziziphi (Jung i sur., 2003). Miličević i sur. (2017) navode da su od bolesti na žižuli kod nas su utvrđene pjegavost lista i različite truleži ploda (antraknoza ploda, alternariozna trulež, moniliozna trulež i dr.) Najznačajniji štetnik je moljac Carpinosa sasakii koji oštećuje plodove.

\section{Sortiment žižule}

U Kini se uzgaja između 700 i 800 različitih sorti žižule. Odabir sorte ovisi o namjeni za koju će se plod koristiti (sušenje, kandiranje, za konzumaciju u svježem stanju ili kombinirano). Postoje i ukrasne sorte koje se koriste za uređenje vrtova. U prošlosti su se većinom uzgajale sorte namijenjene za sušenje, ali selekcijom i uvođenjem novih sorti u porastu su sorte za konzumaciju u svježem stanju (Yao, 2012). Među vodećim sortama su slijedeće:

'Li' - plodovi su veliki i okrugli, dobre kvalitete, težine do 90 g namijenjeni za konzumaciju u svježem stanju. Dozrijeva od početka rujna do sredine listopada.

'Lang' - plodovi su veliki, kruškolikog oblika, namijenjeni su za sušenje. Osjetljivi su na pucanje ukoliko kiši za vrijeme sazrijevanja. Plodovi sazrijevaju tijekom rujna i listopada.

'Sugar Cane' - prvenstveno je namijenjena za ukrašavanje vrtova, no plodovi se mogu konzumirati u svježem stanju ili sušiti. Plod je srednje veličine, okrugao i dobrog okusa. Dozrijeva tijekom listopada. Komercijalno se uzgaja u Kini, dok se u SAD-u mogu pronaći pojedinačna stabla ili nasadi podignuti u svrhu istraživanja.

'Honey Jar' - plodovi su maleni, okrugli i iznimne kvalitete. Veoma slatki i hrskavi namijenjeni za konzumaciju u svježem stanju. Plodnosi u godini sadnje ili cijepljenja. Dozrijeva od sredine do kraja rujna.

'Shanxi Li' -jedna je od najvažnijih sorata za konzumaciju u svježem stanju u Kini. Plodovi su srednje veličine do veliki i dobre kvalitete. Dozrijeva tijekom rujna i listopada.

'GA-866' - plodovi su veliki, izduženi i zašiljeni na vrhovima. Vrhunske kakvoće s visokim udjelom šećera. Uzgaja se u SAD-u. Dozrijeva u isto vrijeme kad i sorta 'Lang'.

'Sihong' - koristi se za konzumaciju u svježem stanju i vrlo je pogodna za sušenje. Uzgaja se u Kini. Dozrijeva sredinom sezone.

'Shanxi Jun' - uzgaja se u provinciji Shanxi, u Kini. Plodovi imaju tanku kožicu i malo sjeme. Zreli plodovi su tamno smeđe boje.

'Abberville' - izuzetno je rodna sorta, no prvenstvena namjena je u svrhu uređenja vrta, jer plodovi ostaju na granama 1 do 3 tjedna nakon opadanja lišća. Plod je osrednje kvalitete. 


\section{Nutritivna svojstva žižule}

Fitokemijski sastav zajedno s informacijama o biološkoj aktivnosti potvrđuje da žižula, ovisno o dijelu biljke, ima različita medicinska i povoljna nutritivna svojstva. Aktivni sastojci ploda žižule su vitamin C, fenoli, flavonoidi, triterpenske kiseline i polisaharidi (Gao i sur., 2011).

Nutritivni sastav ploda žižule ovisi o sorti, fazi zrenja, području uzgoja i ekološkim čimbenicima. Svježi plod sadrži oko $75 \%$ vode (u nekim slučajevima i do $90 \%$ ). U svježem plodu se nalazi oko $20 \%$ ugljikohidrata. Siromašan je bjelančevinama i sadrži ih oko $2 \%$.

Najznačajniji minerali su kalij, fosfor, kalcij i željezo. Žižula je izvor vitamina C, tiamina, riboflavina, niacina, vitamina B-6 i vitamina-A (Gao i sur., 2011).

Glukoza, fruktoza, saharoza, ramnoza i sorbitol predstavljaju većinu šećera koji se nalaze u plodu žižule. Visok sadržaj dijetalnih vlakana i fruktoze imaju ulogu u regulaciji razine šećera u krvi tako što reguliraju probavu (Tahergorabi i sur., 2015). Visok sadržaj polisaharida u plodu žižule ima utjecaj na antioksidativni stres, imunološki sustav, hipoglikemijske aktivnosti, zaštitu gastrointestinalnog trakta te imaju antitumorska svojstva (Ji i sur., 2017).

Plod žižule je izuzetno bogat vitaminom $\mathrm{C}$ u usporedbi sa ostalim voćnim vrstama koje su u širokoj potrošnji (Mahajan i Chopda, 2009; Mousavi i sur., 2016). Sadrži više vitamina C od šipka (Amraei i sur., 2014; Jalili Moghadam i sur., 2012; Khaiati i sur. 2017) i agruma (Kiani Majd i sur., 2013; Yaraei-Rostami i sur., 2013a ,2013b)

Žižula je izvor esencijalnih masnih kiselina. Sadržaj nezasićenih masnih kiselina u plodu žižule se kreće od $68,54 \%$ do $72,44 \%$ od ukupnog sadržaja masnih kiselina. U osušenom plodu žižule se nalaze 33 masne kiseline. Šesnaest masnih kiselina, predominantno 16:1 (7) i $16: 1$ (9) imaju utjecaj na miris ploda žižule (Gusakova i sur., 1999). Najznačajnije masne kiseline u žižuli su: oleinska, linolna i palmitinska. Plod žižule je bogat lipidima, osobito linolnom kiselinom (omega-6) (San i Yildrim, 2010) koju ljudsko tijelo ne može proizvoditi samostalno (Simopoulos, 2008).

Alkaloidi su prisutni u svim dijelovima biljke žižule. Iz kore stabla su izolirani ciklički peptidi: mauritin $A$, mukronin $D$, amfibin $H$, numularin $A-B$, sativanin $A-H i K$, frangulanin, jubanin $A-C$, skutianin C-D i zizifin su izolirani iz kore stabla (Mahajan i Chopda, 2009; Tripathi i sur., 2001). Iz lišća su izolirani alkalodi: koklaurin, isoboldin, norsiboldin, asmilobin, iusifin i iusirin. Peptidni alkaloidi i ciklopeptidi iz žižule imaju sedativna svojstva. Adouetin X, frangulanin i jubanin F-J su ciklički alkoloidi koji imaju sedativan učinak, a izolirani su iz kore korijena (Kang i sur., 2015; Mahajan i Chopda, 2009).

Tri flavonoida: spinosin, 6"'-sinapoilspinosin, 6"'-feruloilspinosin su izolirani i pročišćeni iz žižule (Bai i sur., 2010), a iz sjemenki Ziziphus jujuba var. spinosa je izolirano osam flavonoida. Kemijskom i spektralnom analizom je uspostavljeno da su to: swertish, puerarin, 6"'-feruloilspinosin, apigenin-6-C- $\beta$-d-glukopiranosid, spinosin, $6^{\prime \prime \prime}$-feruloilisospinosin, isospinosin, i isovitexin-2"'-O- $\beta$-d-glucopiranosid (Cheng i sur., 2000).

Prema rezultatima istraživanja Ghobadi i sur. (2019) sadržaji fenola i askorbinske kiseline je veći nego u bilo kojem drugom komercijalnom voću. Utvrđeno je da fizikalno-kemijska i antioksidativna svojstva žižule ovise o sorti (Gao i sur., 2011). Ulje sjemena ima antilisterijska i antioksidativna svojstva (Al-Reza i sur., 2010) dok jestivi dijelovi ploda sadrže fitokemikalije, fenole, flavonoide, alkaloide i glikozide (Al-Saeedi i sur., 2016). Ekstrakt žižule također ima protuupalna svojstva te djeluje na upale izazvane serotoninom i histaminom (Choi i sur., 2011). Antioksidativna aktivnost i imunološki odgovor se kontroliraju inhibicijom proliferacije T-stanica (Sun i sur., 2013; Zhao i sur., 2006).

Esencijalna ulja žižule imaju antimikrobna svojstva dok listovi imaju ljekovita svojstva.

Ekstrakt ploda je imao bolja antimikrobna svojstva na Escherichia coli, Staphylococcus aure- 
us, C. albicans i A. fumigatus od konvencionalnih antibiotika poput Vancomycin-a te dokazano da je dobar kandidat za liječenje infektivnih bolesti osobito u pedijatrijskim slučajevima (Daneshmand i sur., 2013).

Betulinska kiselina izolirana iz stanica kore usporava razvoj HIV 1 infekcije (Mahajan i Chopda, 2009).

Žižula se u Kini tradicionalno koristila za liječenje poremećaja spavanja i anksioznosti. Flavonoidi i saponini iz sjemena su pokazali sedativne i hipnotičke efekte koji su uzrokovali značajno smanjenje vremena hodanja i produžili vrijeme spavanja miševa (Chen i sur., 2017). Polisaharidi i triterpenske kiseline ploda žižule imaju antitumorski učinak i mogu smanjiti umnožavanje stanica tumora (Tahergorabi i sur., 2015).

\section{Zaključak}

Žižula ima izuzetno velik potencijal za uzgoj zahvaljujući otpornosti na temperaturne promjene, malim potrebama u pogledu oborina i kvalitete tla, pogodnostima za ekološki uzgoj zbog nepostojanja prirodnih neprijatelja i njezinoj prilagodljivosti na različite ekološke čimbenike. Iznimno brzo dolazi u rod i ima redovit urod. Plodovi se mogu konzumirati u svježem, osušenom ili prerađenom obliku, dobrog su okusa i bogati vitaminom C. Plodovi i ostali dijelovi žižule (korijen, kora, lišće) imaju dokazano pozitivan učinak na sprječavanje i liječenje određenih bolesti poput dijabetesa, kožnih infekcija, bolesti jetre, upale mokraćnih puteva, pretilosti, vrućice, upale grla, bronhitisa, anemije, nesanice, tumora i smanjenja razine kolesterola.

U budućnosti njezin uzgoj bi se mogao proširiti u Hrvatskoj radi njezine adaptabilnosti na ekološke uvjete, kao i mogućnosti njezina korištenja u prehrambenoj i farmaceutskoj industriji zbog njezine izuzetne kakvoće.

\section{Napomena}

Rad je nastao iz Završnog rada 'Uzgoj žižule' Doriana Sušnja na Sveučilištu u Zagrebu Agronomskog fakulteta.

\section{Literatura}

Al-Reza SM, Yoon JI, Kim HJ, Kim JS, Kang SC. (2010) Anti-inflammatory activity of seed essential oil from Zizyphus jujuba. Food Chem Toxicol. 48(2) 639-643. doi: 10.1016/j.fct.2009.11.045

Al-Saeedi A.H., Al- Ghafri M.T.H., Hossain M.A. (2016) Comparative evaluation of total phenols, flavonoids content and antioxidant potential of leaf and fruit extracts of Omani Ziziphus jujuba L.. Pacific Science Review A: Natural Science and Engineering 18(1)78-83. doi:10.1016/j. psra.2016.09.001

Amraei, A., Miri, S.M., Souri, M.K. (2014) The effect of spray on boric acid on cracking and quantitative and qualitative characteristics of fruit of five pomegranate genotypes in Kuhdasht. M.Sc Thesis of Horticultural Science, Islamic Azad University-Karaj Branch.

Bai H.L., Wang, J., Liu, C.M., Li, L. (2010) Isolation and purification of flavonoids from Ziziphus jujuba by high-speed counter-current chromatography. Journal of the Chinese Chemical Society 57(5A) 1071-1076. https://doi.org/10.1002/ jccs. 201000150

Chen K., Gao L., Li Q., Li H. R., Zhang Y. (2017). Effects of CO2 pretreatment on the volatile compounds of dried Chinese jujube (Zizyphus jujuba Miller). Food Science and Technology 37(4) 578- 584. http://dx.doi.org/10.1590/1678457x.20016.

Chen K.X., Zhao L.M., Ji C.J., Tan N.H. (2015) Flavone C-glycosides from seeds of Ziziphus jujuba var. spinose. Zhongguo Zhong Yao Za Zhi 40(8) 1503-1507.

Cheng G., Bai Y., Zhao Y., Xu X. (2000) Flavonoids from Ziziphus jujuba Mill var. Spinosa. Tetrahedron 56(45) 89158920. https://doi.org/10.1016/S0040-4020(00)00842-5

Choi S.H., Ahn J.B., Kozukue N., Levin C.E., Friedman M. (2011) Distribution of free amino acids, flavonoids, total phenolics, and antioxidative activities of Jujube (Ziziphus jujuba) fruits and seeds harvested from plants grown in Korea. J Agric Food Chem. 59(12) 6594-6604. doi:10.1021/jf200371r

Daneshmand F., Zare-Zardini H., Tolueinia B., Hasani Z., Ghanbari T. (2013) Crude extract from Ziziphus Jujuba fruits, a weapon against pediatric infectious disease. Iranian Journal of Pediatric Hematology Oncology 3(1) 35-40.

Gao Q.H., Wu P.T., Liu J.R., Wu C.S., Parry J.W., Wang M. (2011) Physico-chemical properties and antioxidant capacity of different jujube (Ziziphus jujuba Mill.) cultivars grown in loess plateau of China. Sci Hortic. 130 (1) $67-72$. doi:10.1016/j. scienta.2011.06.005

Guo, Y., Shan G. (2010) The chinese jujube. Shanghai Scientific and Technical Publishers, Shanghai, China.

Ghobadi A., Behbahani F.A., Yousefi A., Shirazi M.T., Behnoud N. (2019) Medicinal and Nutritional Properties of 
Ziziphus jujuba Mill. in Traditional Persian Medicine and Modern Phytotherapy. Crescent Journal of Medical and Biological Sciences 6(2) 146-150.

Gusakova, S.D., Sagudullaev, S.S., Aripov, K.N., Baser, K.H.C., Kurkcuoglu, M., Demirci, B. (1999) Isomers of palmiteolic acid inlipids and volatile substances from the fruits of Ziziphus jujube. Chem. Nat. Compd. 35, 401-403. https://doi. org/10.1007/BF02282503

Jalili Moghadam, Z. Mostafavi, M. and Miri, S.M. (2012) Quantitative and qualitative study of ten genotypes of pomegranate and comparison of their shelf life in the storage. M.Sc Thesis of Horticultural Science, Islamic Azad University-Karaj Branch

Ji X., Peng Q., Yuan Y., Shen J., Xie X. (2017) Wang, M. Isolation, structures, and bioactivities of the polysaccharides from jujube fruit (Ziziphus jujuba Mill.): A review. Food Chemistry 227, 349-357. doi: 10.1016/j.foodchem.2017.01.074.

Jung H.Y., Sawayanagi T., Kakizawa S., Nishigawa H., Wei W., Oshima K., Miyata S.I., Ugaki M., Hibi T., Namba S. (2003)

'Candidatus phytoplasma ziziphi', a novel phytoplasma taxon associated with jujube witches'-broom disease Int J Syst Evol Microbiol. 53 (4)1037-1041. doi: 10.1099/ijs.0.02393-0

Kang K.B., Ming G., Kim G.J., Ha T.K., Choi H., Oh W.K., Sung S.H. (2015) Jubanines F-J, cyclopeptide alkaloids from the roots of Ziziphus jujuba. Phytochemistry. 119: 90-95. https://doi.org/10.1016/j.phytochem.2015.09.001

Khaiati, N. Miri, S.M. and Kalantari, S. (2017) Study of the effect of salicylic acid and Shirazi thyme essence on improving the storage life of pomegranate fruit Malas-e-Saveh. M.Sc. Thesis of Horticultural Science, Islamic Azad University-Karaj Branch.

Kiani Majd S., Miri, S.M., Kalantari S. (2013) Effect of pre-and post-harvest treatment of salicylic acid on shelf life of Pearl Tangelo mandarin. M.Sc. Thesis of Horticultural Science, Islamic Azad University-Karaj Branch.

Liu, M.J., Geng J.X. (1992) A preliminary study on wind-resistant ability of Chinese jujube. Journal of Habei Agricultural University, 17(4) 1-10.

Liu M.J., Wang, W.J., Wen Z.L., Mao Y.M., Zhou J.Y., Xu. H. (1992a) The affection of habitat factor on growing and fruiting of Chinese jujube. Journal of Habei Agricultural University, 15(special issue on Chinese jujube), 45-48.

Liu M.J., Zheng L.K., Bai X.H. (1997) Resistance against wind for Chinese jujube. Journal of Fruit Science, 14(2) 96-99.

Liu M.J. (2002) High quality and high yield cultivation technique of Chinese jujube with color picture illustration.

The Agricultural Publishing House of China, Beijing.

Liu M.J (editor in chief) (2004). Handbook of High-Quality Production of Chinese Jujube, The Agricultural Publishing House of China, Beijing, China, P.1-22, 275-323.

Liu M.J. (2006) Chinese jujube: Botany and horticulture. Horticulture Review, 32, 229-298.

Liu M.J., Wang M. (editor in chief) (2009) Germplasm Resources of Chinese Jujube. China Forestry Publishing House, Beijing, China.

Liu M.J., Zhao Z.H. (2009) Germplasm resources and production of jujube in China. Acta Horticulturae, 840, $25-32$.

DOI: $10.17660 /$ ActaHortic.2009.840.1

Liu MJ, Zhao J, Cai QL, Liu GC, Wang JR, Zhao ZH, et al (2014) The complex jujube genome provides insights into fruit tree biology. Nature Communications, 5, 5315, doi:10.1038/ncomms6315

Lyrene P.M. (1979) The jujube tree. Fruit Var. J. 33:100-104.

Mahajan R.T., Chopda, M.Z. (2009) Phyto-pharmacology of Ziziphus jujuba Mill- A plant review. Pharmacognosy Review. 3(6) 320-329.

Miličević T., Kaliterna J., Vončina D. (2017) Bolesti mediteranskih voćnih vrsta-bajam, rogač, smokva, šipak, žižula. Sveučilište u Zagrebu, Agronomski fakultet, Zagreb.

Miljković I. (1991) Suvremeno voćarstvo. Nakladni zavod Znanje, Zagreb.

Ming W., Sun Y. (1986) Fruit trees and vegetables for arid and semi-arid areas in nortwest China. Journal of Arid Enviroments, 11, 3-16.

Mousavi, S.S. Miri, S.M. and Moradi, P. (2016). Study of jujube micropropagation in in vitro conditions. M.Sc. Thesis of Horticultural Science, Islamic Azad University-Karaj Branch.

Mousavi S.S., Miri S.M., Moradi P. (2017) Optimization of micropropagation of jujube (Ziziphus jujuba cv. Tian-yuzao). Journal of Agronomy and Plant Breeding. 13(4) 1-11.

Prgomet, Ž. (2014) Žižula (Zizyphus jujuba), Poljoprivredni glasnik 5; 3-6.

Qu Z.Z., Wang Y.H. (editor inchief) (1993) Chinese Fruit Trees Record-Chinese Jujube, China Forestry Publishing House, Beijing, China.

San B., Yildirim, A. N. (2010) Phenolic, $\alpha$-tocopherol, $\beta$-carotene and fatty acid composition of four promising jujube (Ziziphus jujube Mill.) selections. J. Food Compos. Anal. 23, 706-710.

Simopoulos A. P. (2008) The importance of the omega-6/omega-3 fatty acid ratio in cardiovascular disease and other chronic diseases. Exp. Biol. Med. 233, 674-688. https://doi.org/10.3181/0711-mr-311

Sun Y.F., Song C.K., Viernstein H., Unger F., Liang Z.S. (2013) Apoptosis of human breast cancer cells induced by microencapsulated betulinic acid from sour jujube fruits through the mitochondria transduction pathway. Food Chem. 138(2-3):1998-2007. doi: 10.1016/j.foodchem.2012.10.079

Tahergorabi Z., Abedini, M.R., Mitra M., Fard M.H., Beydokhti H. (2015) "Ziziphus jujuba": A red fruit with promising anticancer activities. Pharmacognosy Reviews. 9(18) 99-106. doi: 10.4103/0973-7847.162108

Wang B., Huang Q., Venkitasamy C., Chai H., Gao H., Cheng N., Cao W., Lv, X., Pan, Z. (2016). Changes in phenolic compounds and their antioxidant capacities in jujube (Ziziphus jujuba Miller) during three edible maturity stages. Lebensmittel-Wissenschaft Technologie 66, 56-62. http://dx.doi.org/10.1016/j.lwt.2015.10.005

Wu C.S., Gao Q.H., Kjelgren R.K Guo XD, Wang M (2013) Yields, Phenolic Profiles and Antioxidant Activities of Ziziphus jujube Mill. in Response to Different Fertilization Treatments. Molecules, 18, 12029-12040. doi:10.3390/molecules181012029

Yao S. (2012) Jujube: Chinese Date in New Mexico. Guide H-330, New Mexico State University, College of Agricultural, Consumer and Environmental Sciences. https://aces.nmsu.edu/pubs/_h/H330/welcome.html

Yao S. (2013) Unique fruit development of ornamental 'Teapot' jujubé. HortTechnology 23:364-368. https://doi. org/10.21273/HORTTECH.23.3.364

Yaraei-Rostami M., Ghasemnezhad M., Miri S.M., Ghodsvali A. (2013a) Effect of foliar spray with salicylic acid and waxing treatment on quality and storage life of orange fruit cv. Moro. 8th National Horticultural Science Congress of Iran, Hamedan, Iran. 
Yaraei-Rostami M., Ghasemnezhad M., Miri S.M., Ghodsvali A. (2013b) Effect of foliar spray with salicylic acid and waxing treatment on quality and storage life of orange fruit cv. Thamson Navel. $8^{\text {th }}$ National Horticultural Science Congress of Iran, Hamedan, Iran.

Zhou J., Liu M., Hou B. (1998) Advances in research on witches-broom disease of Chinese jujube. J. Fruit Science 15:354-359.

Prispjelo/Received: 17.8.2020. Prihvaćeno/Accepted: 30.9.2020.

Review paper

\title{
Cultivation, nutritional properties, and usage of jujube (Ziziphus jujuba Mill.)
}

\begin{abstract}
Chinese jujube (Ziziphus jujuba Mill.) is a fruit tree that originates from China. It is cultivated for more than 4000 years. Fruit is a drupe which varies in shape (from round to elongated) and size (from cherry like to plum like). Chinese jujube tree is very specific because of its shoot structure and late start of growth and early leaf fall compared to other fruit trees. Fruit is rich in vitamin C and it is essential part of diet in China as well as big part of traditional medicine for treating many illnesses. Chinese jujube can be found in parts of Croatia like Istria and Dalmatia where it is used as a solitary ornamental tree. The best time to plant jujube is in the spring during bud swelling. Jujube harvest begins in late August and lasts until November depending on the variety. Fruiting begins in the second year after planting and gains full yield after 4 to 5 years. In orchards yields ranging from 18 to $50 \mathrm{~kg}$ per tree. Chinese jujube is very interesting fruit for cultivation because of its drought resistance, small demands on soil type and quality and adaptation in Mediterranean climate.

Keywords: nutritional value, production, use, Ziziphus jujuba
\end{abstract}
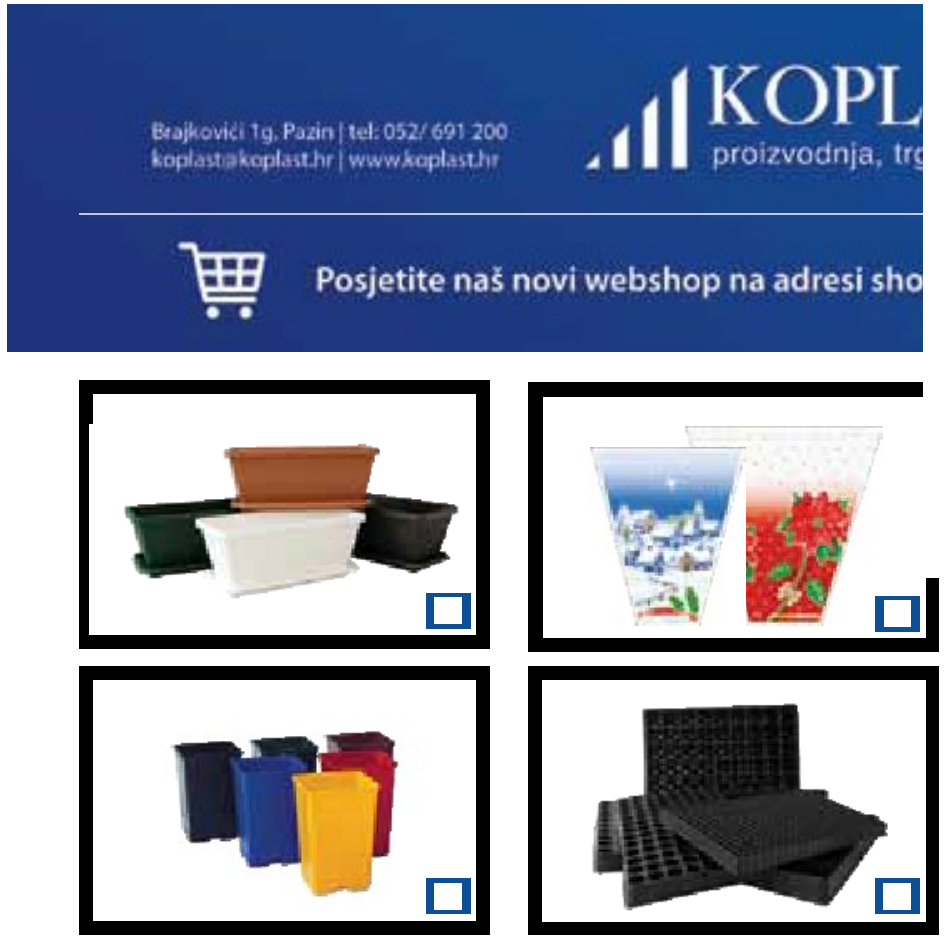

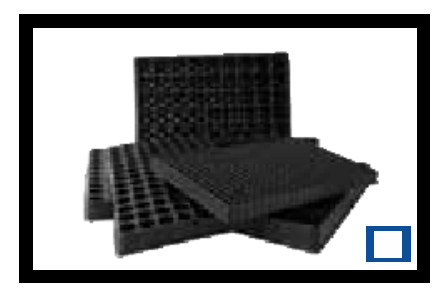

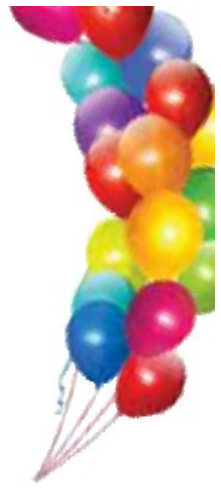

OSTVARITE

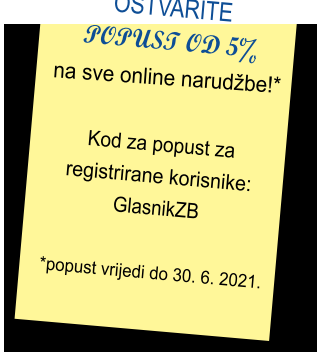

